\title{
Transformações políticas na Colômbia do século XXI: Conflito, Acordo de Paz e seus Efeitos Domésticos e Internacionais
}

\author{
Fernanda Cristina Nanci Izidro Gonçalves ${ }^{1}$
}

\begin{abstract}
Resumo: Ao longo do século XXI, a Colômbia passou por diversas transformações em sua política doméstica e externa. Considerada uma voz dissonante no projeto de integração na América do Sul no alvorecer do novo século, a nação vizinha se inclinou à região a partir de 2010, objetivando romper o afastamento e se integrar de forma mais ativa aos processos sulamericanos, projetando uma identidade renovada. Somou-se a esse cenário o acordo de paz firmado com as Farc, que ajudou a modificar a percepção sobre o país. Este artigo busca analisar os processos políticos internos que afetaram a Colômbia durante este novo século (2000-2019), assim como sua relação com os países da região e sua inserção nos projetos de integração sul-americana. Para tanto, são analisados os governos de Andrés Pastrana (19982002), Álvaro Uribe (2002-2010) e Juan Manuel Santos (2010-2018). Por fim, apresentam-se as mudanças em curso e os desafios encontrados pelo novo presidente, Iván Duque (2018-2019), na política doméstica e exterior, com especial ênfase na política para a América do Sul.
\end{abstract}

Palavras-chave: Colômbia. Política Doméstica. Política Externa.

\section{Political Transformations of Colombia in the 21st Century: Conflict, Peace Agreement and its Domestic and International Effects}

\begin{abstract}
Throughout the 21st century, Colombia went through several transformations in its domestic and foreign policy. Considered a discordant voice in South American integration project at the dawn of the new century, the neighboring nation leaned toward the region from 2010, aiming to reduce the distance and integrate more actively into South American processes by projecting a renewed identity. Adds to this scenario the peace agreement signed with FARC armed group, which helped to change perceptions about the country. This article analyzes the internal political processes that affected Colombia during this new century (20002019) as well as its relationship with the countries of the region and their insertion in South American integration projects. To this end, the governments of Andrés Pastrana (1998-2002), Álvaro Uribe (2002-2010) and Juan Manuel Santos (2010-2018) are analyzed. Finally, the

\footnotetext{
${ }^{1}$ Doutora em Ciência Política (IESP-UERJ), Professora e Coordenadora do Curso de Relações Internacionais do Unilasalle-RJ, Pesquisadora do OPSA e do NEAAPE. Rua Gastão Gonçalves, 79, Santa Rosa - Niterói RJ, 24240030. https://www.unilasalle.edu.br/rj. Email: fernanda.nanci@lasalle.org.br.
} 
ongoing changes and challenges faced by the new president, Iván Duque (2018-2019), in domestic and foreign policy are presented with special emphasis on South American policy.

Keywords: Colombia. Domestic Policy. Foreign policy.

\section{Artigo recebido em: 31/07/2019}

Artigo aprovado para publicação em: 25/11/2019

\section{Introdução}

No início do século XXI, o maior ativismo das relações políticas e econômicas na América do Sul despertou o interesse da academia. Em geral, os estudos apontaram que as eleições de governos de esquerda e centro-esquerda no subcontinente, a partir de 1999, propiciaram mudanças nas políticas domésticas e externas dos países, implicando transformações nas suas relações com os Estados Unidos (EUA) e na intensificação das iniciativas regionais de integração e cooperação (FRAZIER; STEWART-INGERSOLL, 2012; SERBIN; VIGEVANI; HERSHBERG, 2014). Essas iniciativas se basearam na ideia de fortalecer a América do Sul enquanto espaço geopolítico e geoeconômico a partir de processos autóctones, consubstanciando-se no reforço do Mercado Comum do Sul (Mercosul), na criação da União das Nações Sul-Americanas (Unasul), na Aliança Bolivariana para os Povos da Nossa América (Alba), entre outras ações.

Todavia, enquanto alguns Estados sul-americanos convergiram em direção a uma política regional autônoma, sobretudo frente aos EUA, a Colômbia, sob gestão de Álvaro Uribe (2002-2010), aprofundou as relações bilaterais com o país para garantir a cooperação militar e ajuda financeira, visando combater o conflito interno e a guerra às drogas (BORDA, 2013). Assim, o país foi o caso atípico na região, a voz dissonante no projeto de integração na América do Sul no alvorecer do novo século (ARCINIEGAS, 2015). No entanto, com a chegada do presidente Juan Manuel Santos à presidência, em 2010, a nação vizinha se inclinou à região, objetivando diversificar suas relações e atrair investimentos e buscando romper o afastamento e se integrar de forma mais ativa aos processos sul-americanos. 
Ao longo dos últimos dez anos, a Colômbia ganhou maior destaque na América do Sul. Foi o país que mais cresceu economicamente na região e passou a integrar, inclusive, o acrônimo CIVETS $^{2}$, utilizado para se referir a mercados emergentes. No quesito militar, suas Forças Armadas estão entre as mais bem qualificadas no mundo (BORDA, 2014a), o país possui o segundo maior efetivo militar na região e os gastos militares mais elevados em relação ao PIB. No que tange à extensão territorial, é o terceiro maior país na América do Sul e possui uma localização geográfica que facilita uma inserção internacional diversificada com acesso aos oceanos Pacífico e Atlântico, situando-se como uma ponte entre América Central, Caribe e América do Sul. Em termos de demografia, possui a segunda maior população da região, atrás apenas do Brasil, um país quatro vezes maior em extensão territorial. Devido a tais características, a Colômbia tem sido considerada uma potência secundária ${ }^{3}$ em ascensão na hierarquia de poder regional, como indicam Jost, Flemes e Pastrana (2012).

Aliada às características expostas, que indicam algumas das credenciais materiais do país, a Colômbia também passou por intensas transformações políticas ao longo do século XXI, tanto em nível doméstico quanto em sua inserção regional e internacional. De um país caracterizado como subordinado e isolado, "um país problema" (PASTRANA; VERA, 2012), a Colômbia passou a investir nas relações regionais e na modificação de sua identidade em âmbito internacional, buscando se projetar como uma "Nova Colômbia": uma nação capaz de exercer liderança, pelo menos na região, e com grandes aspirações internacionais (BORDA, 2014b). No contexto recente, o discurso de superação da militarização e securitização da política exterior aliado ao acordo de paz firmado com as Forças Armadas Revolucionárias da

\footnotetext{
${ }^{2}$ CIVETS é um acrônimo cunhado por Michael Geoghegan, CEO do HSBC, em 2010, para se referir às seis potências emergentes que seriam a grande aposta para um elevado crescimento econômico nos próximos anos. A sigla se refere à Colômbia, Indonésia, Vietnã, ao Egito, Turquia e África do Sul. Os países possuem similaridades tais como uma jovem população, um mercado consumidor e uma classe média em expansão, assim como elevados índices de crescimento econômico, tornando-se atrativos para investidores (SCHULZ, 2010).

${ }^{3}$ Nos estudos sobre regiões, o termo potência secundária está associado ao conceito de potência regional. Este último é utilizado, de modo geral, para fazer referência a um país que é influente em uma determinada região ou sub-região (NABERS; GODEHARDT, 2011). Na hierarquia de poder regional, as potências secundárias são países que possuem recursos de poder materiais e ideais relativamente menores do que as potências regionais e, portanto, ocupam uma segunda posição de poder na região (FLEMES, 2012b). No caso da América do Sul, o país que mais se aproxima à definição conceitual de potência regional é o Brasil. Para uma discussão sobre o Brasil como potência regional ver Carvalho e Gonçalves (2016).
} 
Colômbia (Farc) alavancam a projeção regional do país, apesar das divergências políticas e ideológicas com alguns vizinhos (em especial, com a Venezuela) e do tradicional alinhamento de sua política externa aos EUA.

Considerando as inúmeras transformações da política doméstica e externa da Colômbia durante este novo século (2000-2018), este artigo tem como objetivo analisar os processos políticos internos que afetaram o país ao longo do período, assim como sua relação com os países da região e sua inserção nos projetos de integração sul-americana. Para tanto, este trabalho está dividido em três seções, além desta breve introdução. A seção seguinte apresenta as prioridades dos governos colombianos nos anos iniciais do século XXI, contemplando os governos de Andrés Pastrana (1998-2002) e Álvaro Uribe (2002-2010), a ênfase na securitização e suas repercussões domésticas e regionais. A próxima seção aborda o governo de Juan Manuel Santos (2010-2018) e as principais mudanças empreendidas ao partir do acordo de paz com as Farc, explorando seus efeitos domésticos e regionais. Por fim, apresenta-se a conclusão do artigo, indicando as mudanças em curso e os desafios enfrentados pelo novo presidente colombiano Iván Duque - empossado em agosto de 2018 - na política doméstica e exterior, com especial ênfase na política regional.

\section{De Pastrana a Uribe: a ênfase no conflito e na securitização}

Existe um consenso na literatura sobre política externa colombiana de que a característica dominante nas relações exteriores foi o alinhamento intencional, pragmático e subordinado aos EUA (TICKNER, 2007; DALLANEGRA, 2012; TOKATLIAN, 2000), que remonta ao início do século XX, após a perda do território do Panamá ${ }^{4}$. A independência deste país, em 1903, é apontada como um evento dramático que expôs a fraqueza da Colômbia frente aos EUA e modificou a percepção de seu papel em âmbito internacional. O país

\footnotetext{
${ }^{4}$ A esse respeito vale lembrar que a Colômbia no século XIX integrava a Gran Colombia, que incorporava os territórios do Equador, da Venezuela, do Panamá e trechos de territórios do Brasil, do Peru e da Nicarágua. Além do Panamá, o país perdeu ao longo de sua história esses diversos outros territórios.
} 
condenou o expansionismo estadunidense, mas em vez de a perda do Panamá significar uma aversão coletiva aos EUA, implicou a busca por diálogo e cooperação (TICKNER, 2007).

As elites nacionais optaram pela adoção de uma política externa dependente, na qual se reconhecia que a hegemonia dos EUA era inevitável e o alinhamento era a estratégia necessária para satisfação dos interesses nacionais. A partir de então, surgiu a chamada Doutrina Suárez, que consolidou a doutrina respice polum, "olhar para a estrela do Norte", ou seja, os EUA ${ }^{5}$ (DREKONJA, 2011). O objetivo era estabelecer relações especiais com a potência, mas o que prevaleceu foi uma relação de subordinação consentida (TOKATLIAN, 2000). A partir de então, o respice polum se consolidou como uma tradição da política exterior colombiana (TICKNER, 2007).

A literatura sustenta que há uma reorientação na política externa em direção à região e outras áreas do mundo a partir da presidência de Lleras Restrepo (1966-1970), que objetivava diversificar as relações do país e ampliar o poder de negociação frente aos EUA. Essa mudança origina outra doutrina presente na história colombiana, a respice similia, que significa "olhar para os semelhantes" (TOKATLIAN, 2000). Desse momento em diante, a política externa colombiana se alternou entre as duas opções, respondendo aos fatores internos e externos que impactavam a formulação da política exterior. Todavia, os problemas domésticos decorrentes do conflito armado e do combate às drogas aprofundados na década de 1980 implicaram a busca por uma cooperação estreita com os EUA nos anos seguintes.

Uma exceção foi o governo de Ernesto Samper (1994-1998), que caracterizou um período de ingovernabilidade doméstica e de dificuldades no relacionamento com os EUA. Seu mandato foi marcado por suspeitas de seus vínculos com narcotraficantes ${ }^{6}$, o que deu origem a uma crise sem precedentes com os EUA, esfriando as relações econômicas e diplomáticas (LAROSA; MEJÍA, 2013). Durante sua gestão, buscou implementar a via da negociação com as Farc; entretanto, diante da deterioração da sua imagem e do país na

\footnotetext{
${ }^{5}$ Essa doutrina foi criada pelo ex-Ministro das Relações Exteriores e ex-presidente colombiano Fidel Suárez, que, ao assumir a presidência em 1918, alterou os rumos da política exterior em direção ao "polo Norte".

${ }^{6}$ Após sua eleição, surgiram evidências de que houve um aporte de cerca de seis milhões de dólares em sua campanha provenientes do cartel de Cali, dando origem ao processo 8.000 , de julgamento do presidente, do qual foi absolvido (LAROSA; MEJÍA, 2013).
} 
comunidade internacional e frente ao recrudescimento da violência - devido à intensificação das ações das Farc em diversas regiões do território - o governo optou pela estratégia coercitiva (RODRÍGUEZ, 2018).

Em termos econômicos, o país também enfrentava graves dificuldades, decorrentes das políticas implementadas para desregulamentação do mercado, que tiveram como efeitos um desemprego crescente e uma forte recessão econômica - aprofundada com as rusgas diplomáticas entre Bogotá e Washington em função das suspeitas sobre o presidente Samper. LaRosa e Mejía (2013) indicam que a recessão durou cerca de cinco anos a partir de 1998, com a economia reduzindo em $4,5 \%$ e a taxa de desemprego chegando a $22 \%$. Em paralelo, as guerrilhas continuavam a se fortalecer e a realizar sequestros.

Andrés Pastrana (1998-2002), membro do Partido Conservador, um tradicional partido colombiano $^{7}$, assumiu a presidência nesse momento, com o país sendo percebido como uma ameaça à segurança regional e global, sendo considerado um Estado pária na região.

\begin{abstract}
A Colômbia se tornou uma anomalia na região; em El Salvador, em 1993, e na Guatemala, em 1996, foram assinados acordos de paz. O Presidente Alberto Fujimori no Peru declarou vitória sobre os rebeldes do Sendero Luminoso com a captura de seu líder, Abimael Guzman, em outubro de 1992. Na Colômbia, no entanto, os envolvidos nos diversos conflitos pareciam mais fortalecidos do que nunca e o Estado parecia ter perdido a liderança (LAROSA; MEJÍA, 2013, p.120, tradução nossa) $)^{8}$.
\end{abstract}

O governo percebeu que os problemas domésticos não poderiam ser solucionados de forma isolada, apesar da visão das Forças Armadas de que a internacionalização do conflito e dos processos de paz poderia implicar um reconhecimento do status de beligerância das guerrilhas por parte do Estado, o que havia sido evitado até então, uma vez que promoveria o

\footnotetext{
${ }^{7}$ Este partido alternou o poder na Colômbia com o Partido Liberal em diversos momentos do século XIX e XX. Entre 1958 e 1974, os partidos se uniram e propuseram a Frente Nacional, que criou uma coalizão que se alternou no poder, evitando a violência existente entre eles na competição pelo poder.

${ }^{8}$ No original: "Colombia se había convertido en una anomalía en la región; en El Salvador en 1993 y en Guatemala en 1996 se habían firmado acuerdos de paz. El presidente Alberto Fujimori en Perú declaró la victoria sobre los insurgentes de Sendero Luminoso con la captura de su líder, Abimael Guzmán, en octubre de 1992. En Colombia, sin embargo, los implicados en los diversos conflictos parecían más atrincherados que nunca, y el Estado parecía haber perdido la delantera" (LAROSA; MEJÍA, 2013, p.120).
} 
reconhecimento político dos grupos (PARDO; CARVAJAL, 2004). Todavia, a proporção da crise humanitária com o aumento exponencial do número de refugiados e deslocados internos, a intensificação da militarização das fronteiras, a mudança da agenda de segurança internacional - que dava maior importância ao narcotráfico como ameaça - e as tentativas frustradas de combater aos grupos armados, fizeram com que Pastrana e sua equipe ministerial optassem por duas frentes de ação: a Diplomacia pela Paz, que implicava negociar com as Farc com apoio da comunidade internacional, e o Plano Colômbia ${ }^{9}$, que buscava modernizar e fortalecer as capacidades das Forças Armadas para o combate ao narcotráfico com apoio dos EUA ${ }^{10}$ (PARDO; CARVAJAL, 2004).

No entanto, a ruptura das negociações com as Farc em 2002 fez com que os esforços fossem concentrados na solução militar do conflito. Nesse ínterim, Pastrana buscou respaldo político internacional, em especial dos EUA e da União Europeia, para expandir o uso dos recursos do Plano para o combate aos grupos guerrilheiros e para obter o reconhecimento dos grupos armados como organizações terroristas ${ }^{11}$, aproveitando-se do contexto do atentado às Torres Gêmeas, em Nova Iorque, em 2001 (PARDO; CARVAJAL, 2004). Assim, a gestão de Pastrana (1998-2002) tratou o narcotráfico como ameaça à segurança nacional e solicitou a cooperação de atores externos, sobretudo dos EUA, para o combate às guerrilhas e às drogas.

É nesse contexto que há a internacionalização do conflito doméstico colombiano, com o início da implementação do Plano Colômbia, ampliando o grau de ingerência dos EUA no país e inaugurando o período que Tickner (2007, p.91) denominou de "intervenção por convite" (intervención por invitación). A cooperação com os EUA ajudou a economia

\footnotetext{
${ }^{9}$ O Plano Colômbia se baseava na assistência técnica, militar e financeira para o combate ao tráfico de drogas, sendo posteriormente expandido para o combate às guerrilhas. $\mathrm{O}$ montante de recursos da ajuda estadunidense chegou a mais de US\$ 8 bilhões (LAROSA; MEJÍA, 2013).

${ }^{10}$ A Colômbia foi o terceiro país que mais recebeu ajuda militar dos EUA, depois de Israel e do Egito. Na região da América Latina e Caribe foi, portanto, o país que recebeu o maior aporte de recursos (TORRES DEL RÍO, 2015).

${ }^{11}$ A vinculação dos grupos guerrilheiros com o tráfico de narcóticos é objeto de discussão na literatura, visto que as ligações não foram claramente definidas. Ao mesmo tempo, tratar a guerrilha como terrorista deslegitima o movimento ao retirar o conteúdo social e político da agenda dos grupos insurgentes, o que ajuda a justificar o uso da força militar (BORDA, 2007).
} 
colombiana a se recuperar, como apontam LaRosa e Mejía (2013), uma vez que houve grande aporte de recursos, sobretudo em assistência militar, ajudando a restaurar a confiança no país.

A eleição de Álvaro Uribe em 2002, ainda no primeiro turno das eleições, representando uma coalizão de direita pelo Movimento Primeiro Colômbia, marcou uma nova etapa na internacionalização do conflito. O lema de sua campanha era "mão dura, coração grande" ("mano dura, corazón grande"), deixando evidente que tomaria uma posição ofensiva contra os grupos armados, adotando tom crítico ao governo de Pastrana pela sua fracassada Diplomacia para a Paz (LAROSA; MEJÍA, 2013). Uribe marcou história à época de sua eleição, sendo eleito no primeiro turno com 53\% dos votos sem estar vinculado aos tradicionais partidos colombianos (Liberal e Conservador).

Com efeito, ao assumir o governo buscou implementar sua proposta de campanha, incrementando as ações militares para combate aos grupos armados. Vinculou o combate às drogas à luta contra o terrorismo em âmbito internacional e apresentou a Colômbia como uma ameaça à segurança regional, ampliando a cooperação militar e a participação estadunidense em operações de combate ao narcotráfico no país. Nesse contexto, o governo colombiano permitiu a fumigação de cultivos ilícitos e a extradição de nacionais para os EUA, suspendo as restrições então existentes. O diagnóstico prevalecente da equipe governamental era de que a fraqueza do Estado gerou condições para que surgissem grupos armados e que era indispensável fortalecer a democracia e as instituições para controlar o território nacional. Surgiu, assim, a Política de Segurança Democrática (PSD) (TICKNER, 2007).

Durante seus dois mandatos, Uribe utilizou das relações públicas para se apresentar como um presidente patriota que não pouparia esforços para derrotar os grupos armados, fossem eles guerrilhas, narcotraficantes ou paramilitares. Ao longo desse período, referiu-se às Farc e ao Exército de Libertação Nacional (ELN) como grupos terroristas, negando-se a considerá-los como atores políticos (LAROSA; MEJÍA, 2013). A característica do período foi, portanto, a militarização e a securitização das políticas antidrogas e de combate às guerrilhas. 
Inclusive, foi durante seu governo que foi lançado o Plano Patriota, a maior ofensiva militar já realizada no país contra atores armados contando com intensa participação estadunidense ${ }^{12}$.

A abordagem militar dos problemas domésticos trouxe diversas dificuldades para o governo de Uribe no plano interno. Entre elas, destaca-se o escândalo dos "falsos positivos", que se refere às execuções extrajudiciais de cidadãos colombianos - apresentados como mortos em combate - pelas instituições armadas. Tais atos ilegais foram fomentados pelos incentivos econômicos de uma política de recompensa nas Forças Armadas em prol do combate ao "inimigo" e pelas pressões do governo para apresentar resultados positivos na luta contra a guerrilha (TORRES DEL RÍO, 2015). Os abusos contra os direitos humanos não pararam nos assassinatos extrajudiciais, uma vez que denúncias de perseguições a líderes sindicais e sociais vieram à tona, gerando a condenação pública de diversas organizações que defendem os direitos humanos, como Human Rights Watch e Anistia Internacional, além de pressões da Comissão Interamericana de Direitos Humanos (CIDH) da Organização dos Estados Americanos (OEA) para com o governo (LAROSA; MEJÍA, 2013; BORDA, 2014a).

Tais episódios tornaram explícito que o discurso patriótico e em tom de vitória do governo em relação aos grupos armados não era realidade absoluta no plano prático, gerando críticas à opção pelo enfrentamento militar. Nesse contexto, o governo Uribe começou a pensar em formas de uma saída negociada para o conflito armado doméstico e buscou negociar um acordo com os paramilitares organizados na Autodefesas Unidas da Colômbia (AUC), dando origem à Lei 975 de 2005, conhecida como Lei de Justiça e Paz ${ }^{13}$. De acordo com essa norma, os paramilitares se desorganizariam, admitiriam seus crimes e receberiam sentenças reduzidas e alternativas, reintegrando-se à sociedade. Contudo, esse processo trouxe à público as violações aos direitos humanos e o envolvimento de diversos militares e

\footnotetext{
12 O Plano Patriota foi lançado em 2003 e consistia em um plano militar que buscava recuperar o território ocupado pelas guerrilhas, principalmente as Farc e o ELN, estabelecendo segurança e controle territorial (LAROSA; MEJÍA, 2013).

${ }^{13}$ Disponível em: < http://www.secretariasenado.gov.co/senado/basedoc/ley_0975_2005.html>. Acesso em: 31 jul. 2019.
} 
indivíduos próximos ao presidente nessas iniciativas, gerando uma grande pressão sobre o governo $^{14}$.

A equipe ministerial de Uribe também tentou iniciar um diálogo secreto com as Farc com apoio dos então presidentes da Venezuela, Hugo Chávez, e do Equador, Rafael Correa. Contudo, as difíceis relações diplomáticas dos mandatários - que divergiam em termos de ideologia e abordagem política - e o ataque ao acampamento das Farc, em 2008, em solo equatoriano inviabilizaram a negociação (LAROSA; MEJÍA, 2013).

Como resultado da estratégia de combate aos grupos armados, houve durante esse período um aprofundamento da dependência dos EUA, que se manifestou não apenas no plano militar, mas também econômico e político. Sob a gestão de Uribe, o governo negociou um Tratado de Livre Comércio com os EUA - que só foi ratificado pelo congresso americano em $2011^{15}$ - e apoiou sua intervenção no Iraque, depondo contra a longa tradição colombiana de respeito ao direito internacional (TICKNER, 2007).

O padrão de relacionamento da Colômbia com os EUA se enquadra no modelo de alinhamento sugerido por Russell e Tokatlian (2009), que se refere ao apoio aos interesses estratégicos dos EUA na região e no mundo, orientado conforme a política estadunidense. Essa relação teve diversas repercussões na vizinhança, entre elas o afastamento colombiano da dinâmica regional e a percepção coletiva de que a Colômbia estava "de costas para a América Latina" (DALLANEGRA, 2012, p.63).

As posições do país contrariavam as dos vizinhos ao longo do governo Uribe. Um exemplo foram as negociações para criação da Área de Livre Comércio das Américas (Alca), pois, enquanto 29 países votaram contra sua criação, a Colômbia apoiou o estabelecimento do organismo. Outro exemplo é na área de segurança, pois, enquanto os países sul-americanos buscavam se desvencilhar das políticas antiterrorismo dos EUA, o país se inseria na estratégia

\footnotetext{
${ }^{14}$ Apesar do desmembramento das Autodefensas Unidas de Colombia (AUC), em muitas regiões do país paramilitares não deixaram de se armar e conduzem ações criminais, exercendo grande influência, sendo conhecidos como bandas criminais (LAROSA; MEJÍA, 2013) ou neoparamilitares (TORRES DEL RíO, 2015).

${ }^{15}$ A demora na ratificação do acordo de comércio se deu em função da grande pressão de líderes sindicalistas, ativistas de direitos humanos e políticos democratas que se posicionavam contra a aprovação, devido às inúmeras violações de direitos humanos que ocorriam no país, como o escândalo dos falsos positivos e o assassinato de líderes sindicais e sociais (LAROSA; MEJÍA, 2013).
} 
estadunidense em âmbito regional e global. Outros desencontros regionais se deram devido ao combate às Farc em zonas fronteiriças, gerando situações delicadas com Venezuela e com Equador, como mencionado, chegando à ruptura das relações diplomáticas.

O episódio mais marcante foi o ataque ao acampamento de Raul Reyes, um dos líderes do grupo armado, em 2008 durante a Operação Fênix, na fronteira com o Equador, que gerou grave crise diplomática, com acusações de desrespeito à soberania do país vizinho e de que Correa e Chávez tinham relações com as Farc. À época, Hugo Chávez enviou tropas para a fronteira com a Colômbia como forma de demonstrar solidariedade com o Equador e durante a $25^{\text {a }}$ Reunião de Consulta de Ministros das Relações Exteriores da OEA, em 2008, foi adotada uma resolução de rechaço à ação militar colombiana. Contudo, a tensão só foi solucionada com o restabelecimento das relações diplomáticas entre os países promovida durante o governo seguinte, de Juan Manuel Santos (LAROSA; MEJÍA, 2013; TORRES DEL RÍO, 2015).

Em 2009, outra crise regional surgiu devido à negociação entre Colômbia e EUA para instalação de bases militares, tema que foi tratado no âmbito da Unasul (DALLANEGRA, 2012). Na ocasião, circularam notícias de que o país poderia se retirar da instituição após questionamentos dos vizinhos. A respeito da Unasul, cabe destacar que houve resistência do governo colombiano quanto à participação no Conselho de Defesa Sul-Americano (CDS) (TUSSIE, 2014), destoando novamente das posições da maioria dos países, que valorizavam a cooperação em defesa promovida pelo órgão.

Ao longo desse período, o alinhamento inflexível da Colômbia aos EUA enfraqueceu sua participação em discussões regionais e sua capacidade de cooperação com os vizinhos. Ao final do governo Uribe, o país estava afastado dos processos regionais em curso, com uma política externa defensiva e com pouca capacidade de influenciar a agenda sul-americana, sobretudo com os escândalos domésticos relacionados à violação de direitos humanos no país 
que, associada às limitadas oportunidades econômicas do período, impulsionaram os colombianos a deixarem o território ${ }^{16}$.

\section{Ventos de mudança: o Governo Santos e o acordo de paz com as Farc}

É diante desse contexto que Juan Manuel Santos assume a presidência, em 2010, com apoio de Uribe pelo Partido Social da Unidade Nacional. O presidente eleito havia sido Ministro da Defesa (2006-2009) durante grande parte do segundo mandato do ex-presidente, demonstrando habilidade política para conduzir crises à frente da pasta. Contudo, apesar de aliado do ex-mandatário, Santos promoveu mudanças significativas na condução da política doméstica e externa, o que promoveu uma ruptura em sua aliança com Uribe, que se tornou seu principal opositor no Congresso, representando o Partido Centro Democrático, o qual criou em 2013 e pelo qual se elegeu como senador em 2014.

Ao assumir a presidência, diferentemente de seu antecessor, Santos (2010-2018) incentivou o estabelecimento de negociações de paz e uma agenda política mais diversificada e menos focada em segurança, apesar da relevância do tema. Reconheceu que o que existia no país era um conflito armado (e não uma ameaça terrorista) e buscou assegurar o compromisso das Forças Armadas com o Direito Internacional Humanitário, como forma de criar uma base para os futuros diálogos de paz (PASTRANA; VERA, 2016). A partir da chamada Política Integral de Segurança e Defesa para a Prosperidade (PISDP $)^{17}$ reconheceu a necessidade de uma estratégia de diplomacia para a segurança que buscasse aumentar a efetividade na luta contra o crime transnacional e reduzir a possibilidade de uma crise regional com países vizinhos, fruto de operações militares realizadas no governo de Uribe (RAMÍREZ, 2012). Assim, adotou postura mais cooperativa, buscando aprofundar sua inserção regional

${ }^{16}$ De acordo com o último relatório disponível do ACNUR, Global Trends Forced Displacement (2017), a Colômbia é o país que possui o segundo maior número de população deslocada no mundo, cerca de 7,9 milhões de pessoas, das quais 7,7 milhões são deslocadas internas (ACNUR, 2017).

17 Essa política envolvia buscar a redução histórica da produção de narcóticos; desarticular grupos armados ilegais; criar condições de segurança para convivência cidadã; avançar em prol de um sistema de capacidades dissuasivas efetivo; contribuir em situações de desastres naturais e catástrofes, fortalecer a institucionalidade e bem-estar do setor de segurança e defesa (PASTRANA; VERA, 2012). 
(ARCINIEGAS, 2015) e reestabelecer as relações com a Venezuela e o Equador, comprometidas desde o governo de Uribe.

Nesse novo contexto, a política externa colombiana foi caracterizada de acordo com o princípio de respice omnia (olhar para o universo) ou respice orbis (olhar para o mundo), que reforça a diversificação das relações exteriores (PASTRANA; VERA, 2012). Nesse cenário, o governo investiu na construção de uma nova identidade, fomentada pela possibilidade de paz frente às negociações internas levadas a cabo com as Farc e pelo contexto econômico de estabilidade e crescimento estimulado pelo setor de mineração, que permitiu ao país resistir à recessão econômica que afetou diversos vizinhos (BORDA, 2014a). A ideia era projetar uma "Nova Colômbia", um país capaz de exercer liderança, pelo menos na região, e com grandes aspirações internacionais (BORDA, 2014b).

Contribuiu para isso a percepção sobre seus recursos materiais e sua posição enquanto potência secundária em ascensão na região. Como afirmou Santos em seu discurso de posse: "A Colômbia é chamada a desempenhar um papel muito importante nos novos espaços globais, e aspiramos a assumir - depois de 40 anos de estar na defensiva - a liderança que nos corresponde" (SANTOS apud PASTRANA; VERA, 2012, p.188, tradução nossa) ${ }^{18}$.

A busca por esse papel de liderança se refletiu em um maior envolvimento político na América do Sul. A gestão Santos buscou restabelecer a confiança nas relações com a Venezuela e com o Equador, trabalhando em prol do restabelecimento de relações diplomáticas com os países. Para tanto, firmou acordos bilaterais e de desenvolvimento fronteiriço. Na região andina propôs o relançamento da Comunidade Andina (CAN), mesmo sem a Venezuela, buscando superar as diferenças ideológicas e diplomáticas no órgão (PASTRANA; VERA, 2012). Também buscou, junto à Venezuela, trabalhar em prol da normalização da situação de Honduras na OEA e fortalecer as relações com o Brasil, gerando uma agenda de cooperação em áreas diversas. Outra iniciativa importante foi intensificar a

\footnotetext{
${ }^{18}$ O trecho original é: "Colombia está llamada a jugar un papel muy relevante en los nuevos espacios globales, y aspiramos asumir - después de 40 años de estar a la defensiva - el liderazgo que nos corresponde" (PASTRANA; VERA, 2012, p. 188).
} 
presença do país na Unasul, ocupando inclusive a Secretaria-Geral do órgão ${ }^{19}$ (DALLANEGRA, 2012).

Diferentemente do governo Uribe, a gestão Santos compreendeu que não existia inconsistência entre ter relações com os EUA e com a região. Assim, a Colômbia adotou um caminho intermediário entre as opções regionais, que excluem os EUA, e as opções que favorecem a cooperação. A intensificação de sua participação na Unasul, simultaneamente à sua participação ativa para criação da Aliança do Pacífico, bloco econômico com o México, Peru e Chile, evidenciam tal aspecto em sua política externa (BORDA, 2014a).

Considerando a via média que o governo colombiano adotou ao longo desse período em suas relações com a região e com os EUA, buscando diversificar parcerias e se estabelecer como um país ponte, o relacionamento bilateral com o tradicional aliado não se enquadrou estritamente na categoria de alinhamento. As relações com os EUA ao longo do mandato de Santos se enquadram melhor na categoria de acomodamento, em que há tentativa de reduzir a dependência. O apoio é seletivo, não mais irrestrito, mas continua existindo um posicionamento de apoio nas instituições, como é perceptível com a posição colombiana de alinhamento aos EUA nas votações da ONU. Em termos de opção estratégica, o país adotou a colaboração seletiva, que, segundo Russell e Tokatlian (2009), consiste na cooperação com a grande potência como meio para solucionar problemas compartilhados e reduzir sua dependência. Diferentemente do governo Uribe, o alinhamento não foi o norte da política externa, todavia não se pode negar que as relações com os EUA permaneceram como grande prioridade para o governo ${ }^{20}$.

No âmbito doméstico, a principal questão da agenda política foi o processo de paz com as Farc, que polarizou o cenário político colombiano ao opor os aliados do presidente aos aliados de Uribe no governo. Após tentativas fracassadas de conciliação em governos

\footnotetext{
${ }^{19}$ O país ocupou a Secretaria-Geral duas vezes: entre 2011 e 2012 com María Emma Mejía, e entre 2014 e 2017 com Ernesto Samper.

20 Apesar de ser prioridade, a postura ao longo do governo de Santos foi distinta, como mencionado. Um exemplo foi o tratamento dado ao tema das drogas, uma vez que houve distanciamento das ações sugeridas pelos EUA e implementadas com Uribe. Santos suspendeu o uso de glifosato, especialmente nas regiões de fronteira, e chegou a criticar na ONU a guerra contra as drogas.
} 
passados $^{21}$, Santos iniciou em 2012 uma nova tentativa de estabelecer um diálogo com a guerrilha, o que enfraqueceu a prioridade da dimensão militar no governo. O processo não foi livre de tensão entre as instâncias civis e as instituições castrenses, que ao vislumbrarem o quanto as Farc estavam enfraquecidas, acreditavam que a melhor opção era continuar com a solução militar. Contudo, a opção de Santos era modificar a abordagem para o conflito doméstico.

Diferentemente das demais negociações realizadas pelos governos precedentes, sua administração optou por envolver os militares nos diálogos com as Farc, como forma de reduzir a desconfiança entre os lados e obter o comprometimento das Forças Armadas, que eram peça chave no processo (ILLERA; RUIZ, 2018). Altos oficiais integraram uma subcomissão com os comandantes da guerrilha para discutir questões logísticas e técnicas relacionadas a aspectos militares do fim do conflito (PASTRANA; VERA, 2016), embora essa participação não tenha dirimido a tensão entre os militares e o governo.

Passados quatro anos de entendimentos, o acordo de paz foi firmado em 26 de setembro de 2016, contando com mediação de Cuba, Venezuela e Noruega. Em busca da legitimação das negociações, esse acordo foi sujeito à plebiscito no dia 02 de outubro, sendo rejeitado por 50,2\% dos eleitores (COLOMBIA, 2019a), influenciados pela campanha contrária ao acordo capitaneada por Uribe e seu partido, Centro Democrático ${ }^{22}$. O governo colombiano voltou à mesa de negociações com as Farc, em Havana, no dia 12 de novembro, em busca da revisão do acordo e da incorporação das demandas feitas por diferentes setores da sociedade. Com cerca de $80 \%$ das reivindicações incorporadas, o acordo foi submetido à aprovação do Congresso, sendo aprovado no dia 24 de novembro. Sua implementação teve início em $1^{\circ}$ de dezembro de 2016 e nesse mesmo ano o presidente Santos foi vencedor do prêmio Nobel da Paz pelos esforços de reconciliação no país.

\footnotetext{
${ }^{21}$ As iniciativas anteriores de negociação foram La Uribe, entre 1982 e 1985, Caracas, em 1991, Tlaxcala, em 1992, e San Vicente del Caguán, entre 1999 e 2002.

${ }^{22}$ Disponível em:

$<$ https://elecciones.registraduria.gov.co/pre_plebis_2016/99PL/DPLZZZZZZZZZZZZZZZZZZ_L1.htm>. Acesso em: 31 jul. 2019.
} 
O processo de negociação foi composto de três etapas. A primeira fase foi exploratória e ocorreu entre fevereiro e agosto de 2012, com negociações secretas entre as partes, resultando em um acordo geral para o término do conflito e para o estabelecimento de uma paz duradoura. Entre outubro de 2012 e setembro de 2016, estabeleceu-se a segunda etapa, chamada de fim do conflito, que contou com mediação internacional e os diálogos em Havana, resultando no acordo final, que foi submetido a plebiscito e revisado para submissão à aprovação do Congresso. A última fase, de construção da paz, iniciou-se com a implementação do acordo em dezembro de 2016 e tem duração prevista de dez $\operatorname{anos}^{23}$.

O acordo de paz é composto de seis pontos centrais: (i) política de desenvolvimento agrário integral; (ii) participação política; (iii) solução ao problema das drogas ilícitas; (iv) vítimas do conflito armado; (v) fim do conflito, (vi) implementação, verificação e referendo. $\mathrm{O}$ primeiro ponto abrange uma reforma rural, buscando reverter os efeitos do conflito no campo, criando condições de bem-estar para a população campesina. O segundo se refere à ampliação da democracia, estimulando a participação política pacífica de diferentes grupos e evitando que armas e política se unam novamente. O terceiro aspecto se baseia na substituição voluntária dos cultivos de uso ilícito e na transformação dos territórios afetados, dando prioridade a um enfoque de saúde pública, combatendo também a cadeia do narcotráfico. $\mathrm{O}$ quarto ponto implica a criação de um Sistema Integral de Verdade, Justiça, Reparação e Não Repetição, de forma a assegurar a prestação de contas e garantir os direitos das vítimas, contribuindo para a reconciliação nacional. O quinto elemento estabelece os termos que marcam o fim do conflito armado, como o cessar fogo bilateral e o cronograma de desarmamento das Farc, dando início à reincorporação de seus ex-combatentes à vida civil. Por fim, o último ponto estabelece um sistema estruturado para monitorar o acordo, incluindo

\footnotetext{
${ }^{23}$ As informações sobre o acordo, bem como sua versão final, estão disponíveis no site da Oficina del Alto Comisionado para la Paz. Disponível em: 〈http://www.altocomisionadoparalapaz.gov.co/Documents/informesespeciales/abc-del-proceso-de-paz/index.html>. Acesso em: 31 jul. 2019.
} 
acompanhamento internacional, por meio da Missão da Organização das Nações Unidas (ONU) no país (COLOMBIA, 2019b) ${ }^{24}$.

A partir da etapa de implementação, diversos foram os obstáculos enfrentados, sobretudo em um cenário caracterizado pela falta de consenso político sobre o acordo de paz, pela preparação para as eleições presidenciais de 2018 e pela baixa popularidade do presidente Santos, cuja imagem ficou bastante deteriorada em função dos escândalos de corrupção envolvendo seu governo e a empreiteira brasileira Odebrecht. Um dos pontos mais problemáticos do acordo reside na Jurisdição Especial para a Paz $(J E P)^{25}$, sujeita à grande pressão das instituições castrenses e dos partidos que se opuseram ao acordo de paz, liderados pelo Centro Democrático, e que questionam a formulação do arcabouço legal para o período pós-conflito, que busca fortalecer a justiça criminal militar (ILLERA; RUIZ, 2018).

Somado a esse aspecto, há também uma discussão sobre a reforma do setor de defesa nesse novo momento, uma vez que implica a transformação da missão, da função e da identidade dos militares, pois no pós-conflito não há mais espaço para a missão do militar focada no combate ao inimigo interno. Nesse aspecto, muitos especialistas têm salientado o grande potencial de colaboração internacional dos militares colombianos pela expertise adquirida ao longo de décadas de confronto armado, podendo cooperar no combate em missões internacionais e em Operações de Paz da ONU (TICKNER, 2016; PASTRANA; VERA, 2016). O ingresso da Colômbia na condição de sócio global na Organização do Tratado do Atlântico Norte (OTAN), em 2018, é uma das conquistas do setor armado nesse novo cenário, aprofundando a cooperação com as Forças Armadas dos países da OTAN em diversas áreas (OTAN, 2018) ${ }^{26}$.

Apesar das dificuldades operacionais da implementação do acordo de paz em diversas áreas - como substituição de cultivos ilícitos, desenvolvimento agrário, incorporação de guerrilheiros à sociedade frente à deserção de alguns e reinserção na luta armada - não se

24 Disponível em: <http://www.altocomisionadoparalapaz.gov.co/Documents/informes-especiales/abc-delproceso-de-paz/index.html>. Acesso em: 31 jul. 2019.

${ }^{25}$ A JEP promove uma reforma constitucional que cria um sistema de justiça para julgar casos de guerrilheiros, militares e civis que tiveram responsabilidades no conflito armado.

${ }^{26}$ Disponível em: < https://www.nato.int/cps/en/natohq/topics_143936.htm>. Acesso em: 31 jul. 2019. 
pode deixar de analisar positivamente os avanços alcançados, como a redução considerável do número de vítimas por ações armadas, o desarmamento da guerrilha, sua incorporação à vida política de forma legal como um partido político (Força Alternativa Revolucionária do Comum) e a conclusão da primeira missão da ONU no país (United Nations Mission in Colombia - UNMCOL), dando origem a uma segunda etapa (United Nations Verification Mission in Colombia).

Desse modo, apesar das dificuldades existentes na implementação do acordo de paz, a Colômbia iniciou uma importante fase de transição de um cenário de conflito e isolamento regional para uma etapa de pós-conflito e de maior inserção na região. Historicamente, o país é caracterizado por uma baixa identidade regional e por uma imagem vinculada à subordinação aos EUA. Contudo, a implementação do acordo e o diálogo de paz iniciado com outro grupo guerrilheiro em fevereiro de 2017, o $\mathrm{ELN}^{27}$, aliados ao discurso do governo - de superação da militarização e da securitização da política exterior - produziram mudanças importantes na imagem da Colômbia no mundo e na região ao longo do governo de Santos.

Assim, o processo de paz trouxe boas perspectivas para o país e para suas relações regionais, devolvendo ao convívio sul-americano um vizinho importante e com grande potencial econômico ${ }^{28}$. Apesar dos inúmeros desafios do cenário pós-conflito e das especulações durante a corrida presidencial de que, se eleito, Iván Duque promoveria mudanças e bloquearia o processo em curso, o atual presidente, membro do Partido Centro Democrático e "afilhado político" de Uribe, vem reiterando o compromisso acordado com as Farc.

\footnotetext{
27 Desde que começaram em 2017, as negociações com o ELN passaram por cinco ciclos e diversos contratempos. O diálogo começou em Quito, no Equador, mas foi transferido para Havana, em Cuba, após casos de violência na fronteira do Equador com a Colômbia, fazendo com que o presidente equatoriano Lenin Moreno decidisse não sediar mais as negociações. Até o momento, as conversações estavam suspensas e sem previsão de retorno após membros do ELN terem assumido autoria do atentado a uma escola de policiais em Bogotá, provocando a morte de 20 pessoas em janeiro de 2019.

${ }^{28}$ É importante destacar que os países da região apoiaram o processo de paz, que foi considerado um dos acontecimentos mais importantes para a América do Sul nos últimos anos. Ademais, o acordo de paz permitiu diminuir as tensões diplomáticas nas regiões de fronteira onde as Farc atuavam.
} 


\section{Considerações finais}

A Colômbia vem transformando sua inserção regional nos últimos anos, buscando se aproximar dos vizinhos e exercer papel mais ativo nos processos regionais, diferenciando-se da imagem de Estado pária que tinha no início do século XXI. No entanto, o país enfrenta grandes desafios para se estabelecer como um possível líder político e econômico na região, embora tenha crescido em capacidades materiais (PIB, efetivo militar, expertise militar) nos últimos anos.

Isso porque o governo colombiano precisa modificar a forma como é percebido, afastando-se dos rótulos de país subordinado aos EUA e isolado dos vizinhos. O cenário doméstico marcado pelo pós-conflito e a recente mudança no quadro político sul-americano com as eleições de presidentes à direita do espectro político (no Paraguai, na Argentina, no Brasil, no Chile, para citar alguns) - vem facilitando a aproximação do governo Duque com suas contrapartes. Além do país externalizar uma imagem renovada no plano internacional, de superação da intensa violência, existe no atual contexto sul-americano uma convergência de visões políticas, econômicas e ideológicas entre diversos governantes que representam a direita.

Exemplo desse novo momento de convergência das visões políticas foi o anúncio da saída da Colômbia da Unasul em agosto de 2018, logo após a posse do presidente Iván Duque, em momento de paralisia da organização. Em abril, junto a outros vizinhos (Argentina, Brasil, Chile, Paraguai e Peru), o país já havia suspendido sua participação nas reuniões do órgão devido a divergências com a Bolívia (que ocupa a presidência pro-tempore do bloco) e Venezuela, o que implicou a impossibilidade de tomada de decisão na organização, uma vez que é necessário o consenso.

No mês de janeiro de 2019, em meio ao aprofundamento da crise venezuelana, frente à paralisa da Unasul e à incapacidade de uma resposta da OEA para solucionar tal situação, o presidente colombiano propôs a criação de uma nova organização regional, chamada 
PROSUL, que funcionará como uma plataforma sul-americana para coordenar políticas públicas e defender os princípios da democracia, as instituições e a economia de mercado. Assim, o novo governo se aproveita do novo momento político na América do Sul e da incapacidade das instituições vigentes de solucionarem a crise venezuelana para se lançar como um interlocutor ativo e possível líder de uma instituição que congregaria os países que possuem governos à direita do espectro político, substituindo a Unasul e o conceito de integração existente até então. Alguns líderes, como Sebastián Piñera, do Chile, manifestaram apoio à proposta.

Contudo, se a ideia é desenvolver uma nova identidade regional e um possível papel de liderança, o governo tem grandes desafios pela frente, como, por exemplo, a crise venezuelana e as relações bilaterais com os EUA, que demandam muito mais que a criação de uma nova instituição regional. A crise venezuelana tem ocasionado intensa migração para a Colômbia, que compartilha uma extensa fronteira com a Venezuela, sendo o país que mais recebeu imigrantes até $\mathrm{o}$ momento ${ }^{29}$. Frente à gravidade do problema e às suas consequências para a Colômbia, seu governo, que deveria ser um dos mais engajados na solução da crise, buscando um chamado ao diálogo, vem agindo de forma oposta, com abertas críticas e pressão constante sobre o país vizinho, articulando com outros governos da região uma posição comum, por meio do Grupo de Lima ${ }^{30}$, para isolar o governo de Nicolás Maduro.

Com relação aos EUA, o novo presidente colombiano vem precisando demonstrar capacidade negociadora para garantir o equilíbrio nas relações com o tradicional aliado e com os seus vizinhos, sobretudo no contexto em que o governo estadunidense, liderado por Donald Trump, indicou que deseja adotar uma posição mais dura no combate ao narcotráfico, devido ao aumento do cultivo de coca na Colômbia (EL TIEMPO, 2018) ${ }^{31}$. Nesse novo cenário, as

\footnotetext{
${ }^{29} \mathrm{Em} 2017$ foram 550.399 imigrantes, enquanto em 2015 eram 48.714. Os outros destinos na região são Argentina $\left(2^{\circ}\right)$, Equador $\left(3^{\circ}\right)$, Chile $\left(4^{\circ}\right)$, Peru $\left(5^{\circ}\right)$ e Uruguai $\left(6^{\circ}\right)$ (OIM, 2018).

${ }^{30}$ O Grupo de Lima foi formado em agosto de 2017 na cidade de Lima, no Peru, durante encontro dos países americanos para discutir a crise venezuelana. O grupo é atualmente formado por Argentina, Brasil, Canadá, Chile, Colômbia, Costa Rica, Guatemala, Honduras, Panamá, Paraguai, Peru, Guiana, Santa Lúcia e México.

${ }^{31}$ Los 'chicharrones' de política exterior que tendrá el próximo Gobierno. El Tiempo. 01/04/2018. Disponível em: < http://www.eltiempo.com/elecciones-colombia-2018/presidenciales/retos-de-politica-exterior-con-que-tendraque-lidiar-el-proximo-gobierno-de-colombia-200162>. Acesso em: 31 jul. 2019.
} 
relações com os EUA podem se encaminhar para a retomada da ênfase no tema da segurança e, nesse ponto de vista, o governo precisará evitar possíveis retrocessos e consequências negativas nas relações com a vizinhança, já atenta à entrada da Colômbia na OTAN como sócio-global.

No âmbito doméstico, os desafios que se apresentam não são menores. $O$ atual governo precisa lidar com o cenário de polarização política, retomar o crescimento econômico, implementar reformas no setor judiciário, na educação e em outras áreas sociais. Também tem de dar continuidade à implementação do acordo de paz com as Farc, sem que prejudique os resultados alcançados, e conter a violência que ainda afeta determinadas regiões que contam com a presença de grupos armados.

A esse respeito, no dia 29 de outubro de 2019, Iván Márquez, guerrilheiro dissidente da extinta Farc, anunciou por meio de um vídeo disponível na internet que começaria uma nova etapa da luta armada. Nas imagens, Márquez apareceu acompanhado de um grupo de homens armados com fuzis e de outros ex-guerrilheiros conhecidos, como Jesús Santrich, contra o qual existe um pedido de extradição para os EUA em andamento na justiça. O governo colombiano respondeu às ameaças, argumentando que por estarem portando armas depois do acordo de paz firmado em 2016, estavam cometendo um grave delito, dando margem para que fosse iniciado um novo processo penal contra eles. Ademais, setores de inteligência do governo argumentaram que há diversos indícios de que o vídeo foi gravado em território venezuelano, onde atualmente estão alguns líderes de outra guerrilha colombiana, o Exército de Libertação Nacional (ELN). No vídeo, inclusive, Márquez afirmou que buscaria coordenar esforços com o ELN para a luta $\operatorname{armada}^{32}$.

A declaração teve repercussão entre as lideranças políticas. O ex-presidente Juan Manuel Santos defendeu a manutenção do acordo de paz e argumentou que $90 \%$ da antiga guerrilha está agindo conforme o negociado, posição compartilhada por Rodrigo Lodoño, ex-

\footnotetext{
${ }^{32}$ Márquez y Santrich reaparecen en video anunciando que vuelven a guerra. El Tiempo. 29/08/2019. Disponível em: $<$ https://www.eltiempo.com/justicia/conflicto-y-narcotrafico/video-ivan-marquez-anuncia-creacion-denueva-guerrilla-406290>. Acesso em: 09 set. 2019.
} 
chefe da guerrilha que lidera o partido político Força Alternativa Revolucionária do Comum, que incorpora os ex-guerrilheiros. Álvaro Uribe - ex-presidente e atual senador - defendeu uma reforma do acordo para rever a penalidade aplicada aos ex-combatentes pela justiça transicional. Os EUA também se manifestaram por meio do seu representante especial para a crise venezuelana, Elliott Abrams, que declarou que tal rearmamento é motivo de grande preocupação para Washington. No dia 09 de agosto, o governo dos EUA já havia manifestado seu apoio ao governo colombiano para promover o desmantelamento do ELN por meio do seu Departamento de Justiça, como evidenciou declaração do vice-procurador-geral dos EUA, Zachary Terwilliger, em seu encontro com o presidente da Colômbia, Iván Duque.

Como se pode perceber, o atual governo colombiano precisa envidar esforços em múltiplas áreas para construir um país de identidade renovada, com estabilidade e crescimento econômico, efetiva segurança e avanços nas suas relações regionais. A complexidade deste novo cenário em âmbito doméstico e externo demanda, na perspectiva da autora, escolhas responsáveis e conscientes, cabendo à atual cúpula governamental implementar, na prática, um novo caminho e não insistir em rotas que já se conhecem o resultado. Assim, fica a questão: o país vai rumo ao futuro ou de volta ao passado? A esperar os próximos passos do novo governo para identificar se as opções domésticas e internacionais conduzem a Colômbia a um novo cenário doméstico caracterizado pelo pós-conflito e por mudanças em suas relações exteriores ou se haverá um retorno às práticas de securitização e militarização da política doméstica com impactos já conhecidos na agenda externa e, sobretudo, regional.

\section{Referências Bibliográficas}

ACNUR. Global Trends Forced Displacement. 2017. Disponível em: < https://www.unhcr.org/globaltrends2017/>. Acesso em: 31 jul. 2019.

ARCINIEGAS, Alexander Carreño. El acuerdo de paz en Colombia y sus posibles impactos para Brasil y la región. Observador On-Line, v.10, n.2, p. 1-15, 2015. 
BORDA, Sandra. La internacionalización del conflicto armado después del 11 de septiembre: ¿la ejecución de una estrategia diplomática hábil o la simple ocurrencia de lo inevitable? Colombia Internacional, n. 65, jan-jun., p. 66-89, 2007.

Escenarios posibles frente al proceso de paz colombiano. Efectos internos y regionales. Memoria, FES-Seguridad, p. 1-7, 2013. Disponível em: $<$ https://library.fes.de/pdffiles/bueros/la-seguridad/10153.pdf>. Acesso em: 01 jun. 2019.

Estrategias y potencialidades en relación al Sistema Interamericano: La política exterior de Colombia. In: HERSHBERG, Eric; SERBIN, Andrés; VIGEVANI, Tullo. Pensamiento Próprio: El hemisferio en transformación: Regionalismo, multilateralismo y políticas exteriores en un entorno cambiante. Buenos Aires: CRIES, ano 19, jan-jun, p. 327352, 2014a.

Política exterior de la administración Santos: un liderazgo de vía media para Colombia. In: BORDA, Sandra; FLORIANO, Fábio; MOY, Valeria; PALLARES, Maria; AYUSO, Anna. Liderazgos regionales emergentes en América Latina: Consecuencias para las relaciones con la Unión Europea. Barcelona: Barcelona Centre for International Affairs CIDOB, nov, p. 29-39, 2014b.

CARVALHO, Patrícia Nasser de; GONÇALVES, Fernanda Cristina Nanci Izidro. O Brasil como potência regional: uma análise de sua liderança na América do Sul no início do Século XXI. Revista Carta Internacional, Belo Horizonte, v. 11, n. 3, p. 222-248, 2016.

COLOMBIA. Ley de Justicia y Paz, 2015. Disponível em: < http://www.secretariasenado.gov.co/senado/basedoc/ley_0975_2005.html>. Acesso em: 31 jul. 2019.

COLOMBIA. Registraduría Nacional, 2019a. Disponível em: < https://elecciones.registraduria.gov.co/pre_plebis_2016/99PL/DPLZZZZZZZZZZZZZZZZZ_

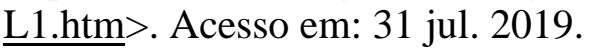

COLOMBIA. Alto Comisionado para la Paz, 2019b. Disponível em: $<$ http://www.altocomisionadoparalapaz.gov.co/Documents/informes-especiales/abc-delproceso-de-paz/index.htm>. Acesso em: 31 jul. 2019.

DALlANEGRA, Luis. Claves de la política exterior de Colombia. Revista de Estudios Latinoamericanos, n.54, p. 37-73, 2012.

DREKONJA, Gerhard. Formulando la política exterior colombiana. In: BORDA, Sandra; TICKNER, Arlene. Relaciones internacionales y política exterior de Colombia. Bogotá: Universidad de los Andes, Facultad de Ciencias Sociales, 2011, p. 49-78. 
EL TIEMPO. Los 'chicharrones' de política exterior que tendrá el próximo Gobierno. 01/04/2018. Disponível em: <http://www.eltiempo.com/elecciones-colombia2018/presidenciales/retos-de-politica-exterior-con-que-tendra-que-lidiar-el-proximogobierno-de-colombia-200162 >. Acesso em: 31 jul. 2019.

FLEMES, Daniel. Actores estatales y regionalismo estratégico: Brasil y Colombia en el orden multipolar. In: JOST, Stefan; FLEMES, Daniel; PASTRANA, Eduardo (Org.). Colombia y Brasil: ¿socios estratégicos en la construcción de Suramérica? 1. ed. Bogotá: Editorial Pontificia Universidad Javeriana, Fundación Konrad Adenauer, German Institute of Global and Area Studies (GIGA), Universidad San Buenaventura, 2012a, p. 25-50.

La política exterior colombiana desde la perspectiva del realismo neoclássico. In: JOST, Stefan. Colombia: ¿ una potencia en desarrollo? Escenarios y desafíos para su política exterior. 1. Ed. Bogotá: Fundação Konrad Adenauer Colômbia; Opciones Gráficas Editores, 2012b, p. 19-38.

FRAZIER; Derrick; STEWART-INGERSOLL, Robert. Regional Powers and Security Orders: A Theoretical Framework. 1. ed. New York: Routledge Global Security Studies, 2012.

GODEHARDT, Nadine; NABERS, Dirk. Introduction. In: FRAZIER; Derrick; STEWARTINGERSOLL, Robert (Org.). Regional Powers and Regional Orders. 1. ed. Londres: Routledge, 2011, p. 45-69.

ILLERA, Olga; RUIZ, Juan Carlos. Entre la política y la paz: las Fuerzas Militares tras la firma del Acuerdo de Paz. Revista Iberoamericana de Filosofía, Política y Humanidades, n. 39, ano 20, p. 509-533, 2018.

JOST, Stefan; FLEMES, Daniel; PASTRANA, Eduardo. Prólogo. In: JOST, Stefan; FLEMES, Daniel; PASTRANA, Eduardo (Org.). Colombia y Brasil: ¿socios estratégicos en la construcción de Suramérica? 1.ed. Bogotá: Editorial Pontificia Universidad Javeriana, Fundación Konrad Adenauer, German Institute of Global and Area Studies (GIGA), Universidad San Buenaventura, 2012, p. 13-22.

LAROSA, Michael J.; MEJÍA, Germán R. Historia concisa de Colombia (1810-2013). 1. ed. Bogotá: Universidad del Rosario; Pontificia Universidad Javeriana, 2013.

NOLTE, Detlef. Regional Powers and regional governance. In: GODEHARDT, Nadine; NABERS, Dirk (Org.). Regional Powers and Regional Orders. 1.ed. Londres: Routledge, 2011, p. 80-120. 
OIM - Organização Internacional para as Migrações. Tendencias Migratorias Nacionales en América del Sur, 2018. Disponível em: <https://robuenosaires.iom.int/>. Acesso em: 31 jul. 2019.

OTAN. Organização do Tratado do Atlântico Norte. Disponível em: < https://www.nato.int/cps/en/natohq/topics_143936.htm>. Acesso em: 31 jul. 2019.

PARDO, Rodrigo; CARVAJAL, Leonardo. Relaciones Internacionales, Conflicto Doméstico y Procesos de Paz en Colombia. In: LONDOÑO, Patti; CARVAJAL, Leonardo (Org.). Violência, Paz e Política Exterior en Colombia. 1. ed. Bogotá: Universidad Externado de Colombia, 2004, p. 153-234.

PASTRANA, Eduardo; VERA, Diego. Estrategias de la política exterior de Colombia en su calidad de potencia secundaria de Suramérica In: PASTRANA, Eduardo; VERA, Diego (Org.). Colombia y Brasil: ¿socios estratégicos en la construcción de Suramérica? Bogotá: Editorial Pontificia Universidad Javeriana, Fundación Konrad Adenauer, GIGA, Universidad San Buenaventura, 2012, p. 187-236.

La política exterior colombiana de cara al proceso de paz y el posconflicto. In: PASTRANA, Eduardo; GEHRING, Hubert (Org.). Politica exterior colombiana: escenarios $y$ desafios en el posconflicto. $1^{\text {a }}$ ed. Bogotá: Pontificia Universidad Javeriana; Fundación Konrad Adenauer, 2016, p. 61-90.

RAMÍREZ, César. Anatomía de un actor: el Ministerio de Defensa Nacional y la política exterior colombiana. In: JOST, Stefan (Org.). Colombia: ¿una potencia en desarrollo? Escenarios y desafíos para su política exterior. Bogotá: Fundação Konrad Adenauer Colômbia: Opciones Gráficas Editores, 2012, p. 211-226.

RODRÍGUEZ, Saúl. Building civilian militarism: Colombia, internal war, and militarization in a mid-term perspective. Security \& Dialogue, v. 49, n.1-2, p.109-122, 2018.

RUSSELL; Roberto. TOKATLIAN, Juan. Modelos de política exterior y opciones estratégicas El caso de América Latina frente a Estados Unidos. Revista CIDOB D'Afers Internacionals, n.85-86, p. 211-249, 2009.

SANTOS, Juan Manuel. Discurso del Presidente Juan Manuel Santos Calderón. Sistema Informativo del Gobierno, 7 de agosto de 2010. Disponível em: $<$ http://wsp.presidencia.gov.co/Prensa/2010/Agosto/Paginas/20100807_15.aspx >. Acesso em: 31 jul. 2019.

SCHULZ, Nils-Sjard. The third wave of development players. Policy Brief. FRIDE - A European Think Tank for Global Action, n.60, nov., p. 1-5, 2010. 
TICKNER, Arlene. Intervención por Invitación: Claves de la política exterior colombiana y de sus debilidades principales. Colombia Internacional, n.65, jan-jun, p. 90-111, 2007.

Exportación de la seguridad y política exterior de Colombia. Bogotá: FriedrichEbert-Stiftung, n. 12, set., p. 1-32, 2016.

TOKATLIAN, Juan. La mirada de la política exterior de Colombia ante un nuevo milenio: ¿Ceguera, miopía o estrabismo?, Colombia Internacional, n.48, jan-abr, p. 35-43, 2000.

TORRES DEL RÍO, Cesar Miguel. Colombia siglo XX: desde la guerra de los Mil Días hasta la elección de Álvaro Uribe. 1. ed. Bogotá: Pontificia Universidad Javeriana, 2015.

TUSSIE, Diana. Reshaping Regionalism and Regional Cooperation in South America. In: HERSHBERG, Eric; SERBIN, Andrés; VIGEVANI, Tullo (Org.). Pensamiento Próprio: El hemisferio en transformación: Regionalismo, multilateralismo y políticas exteriores en un entorno cambiante. Buenos Aires: CRIES, ano 19, jan-jun, p. 109-136, 2014. 